\title{
Epistemic practices in professional-client partnership work
}

\author{
Nick Hopwood (University of Technology Sydney) \\ Monika Nerland (University of Oslo)
}

Paper accepted for publication in Vocations and Learning.

\begin{abstract}
Relational aspects of professional practice demand increasing attention in research on work and learning. However, little is known about how knowledge is enacted in practices where different people work together. Working in partnership with clients surfaces a number of epistemic demands, responses to which are poorly understood. This paper analyses two cases of nurses working with parents in support services for families with young children. The questions asked are: What epistemic practices are enacted when professionals work in partnership with clients? How do they generate distinct modes of partnership work? Findings show how professionals' and clients' knowledge is mobilised and made actionable through practices of diagnostic reasoning, recontextualising, testing and contesting knowledge claims. A distinction is presented between partnership that unfolds as strengthening the client from a professional epistemic perspective, and that which validates and augments the client's own epistemic contribution. This reveals how knowledge is made to matter and becomes a basis for action in the course of working with others, and informs a new analytical distillation highlighting key epistemic aspects of professional-client partnership.
\end{abstract}

Keywords

Partnership; professional knowledge; epistemic practices; professional practice; parenting

\section{Introduction}


Connections between knowledge, practice and learning at work have been a key focus since the inaugural issue of this journal (Nerland 2008; Gartmeier et al. 2008; Fenwick 2012b). However, there remains a need to develop fresh theoretical accounts of how professional work is done (Evetts 2014), especially so in contexts of professional-client partnership. Expectations of working in closer and more complex relationships with others form part of wider forces that challenge professional expertise (Prior 2003). These changes are evident in concern with inter-professional practice (Guile 2011), inter-agency work (Edwards et al. 2009), co-production with clients (Fenwick 2012a), and how professionals relate to communities and government (Billett et al. 2007). Such relationships alter what it takes to perform professional work, generating demands associated with what Edwards (2010) calls a 'relational turn' in expertise.

Although these trends are generally acknowledged, aspects of how professional practice is accomplished remain 'hazy, if not invisible and underestimated' (Markauskaite \& Goodyear 2014, p. 80), particularly where professionals work with, not just for clients (Grundman 2017). Forms of joint work and collaboration between professionals and clients are often referred to as 'partnership' (Smith et al. 2015) ${ }^{1}$. Here, demands for expert knowledge meet demands for clients to be more actively engaged in the process (Guile 2010).

This paper focuses on the professional work that is enacted when parents seek help from professionals through child and family health services, specifically through support from nurses who visit in their homes (home visiting), or through a series of visits to a clinic (day stay). Parents are increasingly seeking expert help relating to parenting (Aarsand 2014), but as parenting is such a highly sensitive topic, the use of expertise is particularly challenging in these contexts. Consequently, parenting support services in many countries have adopted partnership approaches. Partnership means joint but not necessarily symmetrical work in which the knowledge and experience of both the professional and parent are valued and brought to bear, constituting the parent as a source of change, object of practice, and partner (Day et al. 2015).

Partnership in parenting support services has spread across much of Europe, North America and Australasia. This has been driven by recognition of the problems when professionals tell parents what to do or solve problems on their behalf: parents feel judged and that their knowledge is not respected (Eronen et al. 2010). Aspects of partnership relating to 
communication and inter-personal relationships have been specified in models, such as the Family Partnership Model (FPM; Day et al. 2015). The FPM was developed at the Centre for Parent and Child Support in the UK, and combines a model of an iterative helping process with in-service training for professionals and volunteers. The FPM focuses on communication and negotiation, describing relationships between professionals and clients, and qualities that contribute to these such as empathy, active listening, and positive regard for parents. Prior analyses of practices where FPM was implemented revealed partnership to be enacted in different ways. Relationships between exploring the problem, developing new meanings, embodied caregiving, and future planning varied from case to case (Hopwood 2016). Partnership reflects the contingencies and dynamics specific to each family (Hopwood \& Edwards 2017). However, research shows professionals can experience difficulty wielding their expertise under the rubric of partnership (Grundmann 2017).

Neither models like FPM nor prior research have clarified how professionals and parents handle knowledge. The epistemic dimensions of partnership remain unclear. This paper documents the enactment of partnership in concrete work settings, and addresses this gap by asking: What epistemic practices are enacted when professionals work in partnership with clients? How do these practices position participants and generate distinct modes of partnership work? Specifying distinctions between two cases, we then highlight key epistemic aspects of professional-client partnership.

\section{An epistemic practices perspective}

An epistemic practices perspective is useful for conceptualising how knowledge is generated, shared and enacted in professional work (Knorr Cetina 2001; Nerland \& Jensen 2014). At issue are the ways knowledge claims are proposed, communicated, justified, assessed and legitimised (Cunningham \& Kelly 2017). Attention is paid to how knowledge is activated and becomes actionable, as well as to how positions as knowers are taken in interaction (Jensen et al. 2015; Gherardi 2006; Goodyear \& Markauskaite 2016) Questions of epistemic practice therefore concern how work is done and the learning implicated in this accomplishment. 
This perspective locates knowledge work in practical action. Epistemic practices involve knowledge-centred work that 'shifts back and forth between the performance of "packaged" routine procedures and differentiated practice' (Knorr Cetina 2001, p. 178). Learning is implied in such dynamics, as knowledge is co-constructed and participants handle questions of what knowledge counts and how it is made to matter (Nerland 2008; Ericksson \& Lindberg 2016). Epistemic practices evolve with each new knowledge-related situation (Knorr Cetina \& Reichmann 2015). However, they are also shaped by the work context to which they relate: Nerland and colleagues (Damşa \& Nerland 2016; Jensen et al. 2012) mapped domain specific differences in ways of doing knowledge work in engineering, teaching, nursing, accountancy and law. In their review of research taking this approach, Nerland and Jensen (2014) note three broad foci. The first concerns higher education as a site of professional formation - formal education or training for future work. The second involves studies focusing on particular professions, and the third explores knowledge production in inter-professional or inter-agency settings. However, this perspective has not been taken up in detailed studies of professional-client partnerships.

Such partnerships are epistemically demanding in several ways. Epistemic demands arise when professionals share responsibilities with clients (Markauskaite \& Goodyear 2016), requiring a capacity to participate in joint creation of actionable knowledge - i.e. knowledge that enables oneself and the client to act more knowledgeably. Guile (2014) found mixed groups of professionals needed to determine ways of working together specific to each particular project, and the same applies to professional-client partnerships (Hopwood 2016, 2017a, 2017b). Partnership requires professionals and clients to co-create the epistemic environments needed to support their own learning and knowing as work unfolds (Markauskaite \& Goodyear 2014). The precise way forward varies each time (Hopwood 2017a, 2017b).

Second, child and family health professionals' knowledge of families is typically incomplete, fragile and of uncertain status (Hopwood 2016). A demand arises to explore knowledge issues beyond what is already known, question the validity of knowledge claims, test their feasibility, and implications for action. Knowledge in partnership practices is not static, but is constructed and worked on as professionals work with clients. 
Epistemic demands in partnership also concern the status of professional expertise and appropriate uses of it when working with parents (Grundmann 2017). Studies from the UK (Harris et al. 2014), Finland (Juhila et al. 2016), Netherlands (van Houte et al. 2015) and Australia (Fowler et al. 2012) show that professionals seeking to work in partnership can feel torn between two problematic positions. Activating specialist knowledge can undermine partnership, positioning professionals as bossy experts who control the agenda and have all the answers. A retreat from expertise is equally problematic. Professionals must remain connected to clients' experiences, listen to parents' concerns, value their knowledge, and respect their autonomy, while maintaining purpose and facilitating change (Smith et al. 2015). Asymmetries in experience and skills are not eliminated in partnership.

In order to open up partnership practices for an epistemic analysis, we make use of the following analytical resources. First, epistemic practices include ways of framing problems epistemically as specific types of problems. Problem framing is critical to professional expertise and to mediating the use of epistemic resources in practice (Schön 1987), hence the importance of tracing how knowledge is mobilised to frame problems, for instance, whether the problem is understood as a matter of social relations or biological states, or whether it is seen as more persistent or occasional. Such framing draws on epistemic resources and has implications for what kind of knowledge becomes relevant to address the problem (Shaffer 2006).

Second, framing and further exploring problems depends on how epistemic resources are activated and made legitimate in the process. Epistemic resources can include specialised knowledge, personal experience, empathic insights, procedures for diagnosing, planned sequences of acting, and tools used to organise and display knowledge, such as charts showing milestones in children's development. The status of these and how they are made actionable (i.e. possible to put to work in relation to a particular problem or concern) may rely on other epistemic resources, as well as on the epistemic framing.

Third, ways of activating epistemic resources to specific problems are not straightforward. Threads of such practices are understood as 'woven twice' (Knorr Cetina 2006) as experiences from other contexts are related to a given situation. It is not simply a question of inserting existing knowledge into a new situation, but recontextualising it to become relevant and adapted to specific contexts (Guile 2010). How such recontextualisation gets done in 
professional-client partnership is not well documented. Finally, during the work on problem situations, knowledge and solutions need to be tested out and assessed for their feasibility, which involves a back-and forth movement generalised knowledge and the between specific context. In the analysis that follows, we draw on these four broad a priori categories of epistemic practices to investigate inductively how epistemic practices are enacted in two cases.

\section{Empirical context, data and analytical approach}

\section{Institutional and service context}

The data analysed here constitute 71 observations of professional-client interactions in two kinds of parenting support services in Sydney, Australia. Professionals participating in the study were qualified nurses, many with specialisms relating to child and family health (e.g. Lactation Consultants). They were employees of Karitane, Tresillian, or Northern Sydney Local Health District (ethics approval was given for these institutions to be named, but not individuals within them). Northern Sydney Local Health District offers a range of services, including child and family health, directly under the NSW Ministry of Health. Karitane and Tresillian are Affiliated Health Organisations, providing Recognised Services (which gives them formal connection with the Ministry of Health) in child and family health, each operating across several Local Health Districts. Support for parents with young children is typically provided by nurses and community health practitioners, alongside social workers, counsellors and psychologists. Between and within countries, such services sit differently in broader health and social service organisational structures, referred to variously as child and family health, community health for children and families, maternal and infant health, and child health and parenting.

This paper focuses on professional-client (nurse-parent) interactions in two kinds of child and family health services. Both were offered by all three institutions, were free of charge to families, and entered into on a voluntary basis by parents. Day stay clinics are attended by parents initially for a full day (up to seven hours), then for one or two shorter visits. Each family is assigned a nurse who works with them throughout the stay, providing support around breastfeeding, sleep and settling, and sometimes toddler behavior management. Parents may see a counsellor or social worker during a visit. Observations were carried out in four day stays across the three institutions. Two of these were purpose-built, shared grounds 
with other health services and had a more clinical feel. The others were converted premises, one close to high street shops, one a former house in a quiet residential area.

The second service setting was home visiting. One-off visits to mothers close to the time of birth are common (referred to as universal home visiting, or health visiting in some countries). The services studied here distinctive because they targeted families where additional support was needed, and involved multiple visits by a nurse to a family home over several weeks or months. Visits usually lasted around one hour.

All the institutions and services involved had taken steps to adopt partnership approaches, specifically through the FaFPM (Day et al. 2015). FPM Foundation training, a 10-day course focused on communication skills, negotiation, and relationship-building, had been made available to staff in all three, and had been completed by all participating nurses.

\section{Data collection and analysis}

Information about the study was sent to nurses working in relevant services in each organisation. Several opted in and gave consent from each, after which families assigned to those nurses were asked for consent.

Data comprised field notes written during the observed interactions, typed up and expanded immediately afterwards. The field notes captured detailed accounts of spoken interactions, physical gestures and objects referred to (such as sleep guides for parents). Observations lasted for the duration of each professional-client meeting, ranging from 1 hour to 7 hours.

An epistemic practice perspective allows for analytically 'magnifying knowledge in action', focusing on processes of knowing and their connections with knowledge practices and resources (Nerland \& Jensen 2014). We took interaction as the unit of analysis (Säljö 2009; Damşa \& Nerland 2016), looking at how the knowledge of professionals and clients was mobilised as they co-produce responses to complex problems. To allow necessary attention to detail, we analysed two interactions, one from a day stay service and one from a home visit. They were selected because they instantiate different ways of enacting partnership. Details of each case are provided in Table 1 - Catherine's first contact with Ariella in a day stay, and Sophie's visit to Masha's home, several encounters into their relationship. 
Table 1

Details of examples

\begin{tabular}{|c|c|c|}
\hline Aspect & Catherine \& Ariella & Sophie \& Masha \\
\hline Service & $\begin{array}{l}\text { Day stay: parents visit for 5-7 hours, } \\
\text { up to } 3 \text { times over several weeks }\end{array}$ & $\begin{array}{l}\text { Home visiting: nurse visits home for } 1-2 \\
\text { hours, from weekly to monthly over } \\
\text { several months }\end{array}$ \\
\hline Family details & $\begin{array}{l}\text { Ariella is mother of Lila, aged } 16 \\
\text { months; has a } 20 \text {-year old son from a } \\
\text { prior marriage who lives with her ex- } \\
\text { husband who had been abusive; Ariella } \\
\text { and her current husband had recently } \\
\text { taken on care of his 9-year old } \\
\text { daughter Rosie; Ariella had a history } \\
\text { of depression }\end{array}$ & $\begin{array}{l}\text { Masha is mother of Morgan, aged } 10 \\
\text { weeks; Morgan is the first born to } \\
\text { Masha and her husband David, neither } \\
\text { of whom had prior marriages or } \\
\text { offspring; David had recently stopped } \\
\text { taking medications for depression } \\
\text { feeling they hadn't helped }\end{array}$ \\
\hline $\begin{array}{l}\text { Reasons for } \\
\text { parent seeking } \\
\text { professional } \\
\text { support }\end{array}$ & $\begin{array}{l}\text { Ariella sought help getting Lila to } \\
\text { sleep and to remain asleep, as Lila's } \\
\text { unsettled behavior was causing } \\
\text { maternal exhaustion; Ariella had high } \\
\text { levels of anxiety and felt unable to } \\
\text { return to work (screening revealed } \\
\text { recent thoughts of self harm) }\end{array}$ & $\begin{array}{l}\text { Masha sought help addressing acute } \\
\text { anxiety that something bad would } \\
\text { happen to Morgan (e.g. he had recently } \\
\text { had bronchiolitis); this connected with } \\
\text { practical issues that varied from visit to } \\
\text { visit, with many being raised each visit: } \\
\text { Masha was unable to leave house due to } \\
\text { fear of a road accident; concerned about } \\
\text { Morgan's unsettled behavior, rashes etc. }\end{array}$ \\
\hline $\begin{array}{l}\text { Relationship } \\
\text { history between } \\
\text { professional and } \\
\text { client }\end{array}$ & $\begin{array}{l}\text { First contact between the two was } \\
\text { observed. Catherine received brief } \\
\text { information in referral documentation } \\
\text { describing the reason for referral and } \\
\text { some relevant medical and family } \\
\text { history. The first visit included an } \\
\text { admission process, screening for } \\
\text { depression and domestic violence, } \\
\text { before moving on to moves on to a } \\
\text { focus on sleep and settling }\end{array}$ & $\begin{array}{l}\text { Sophie had visited Masha several times; } \\
\text { receiving standard referral information } \\
\text { previously, and completing admission } \\
\text { documentation in the first visit; by this } \\
\text { stage Sophie knew Masha well, although } \\
\text { Masha's concerns changed frequently. } \\
\text { In the observed interactions, Masha } \\
\text { raised a number of issues that they } \\
\text { worked on together. }\end{array}$ \\
\hline
\end{tabular}


Analysis involved a number of steps. First the authors each produced a holistic summary of key features of interest and contrasts between the two cases. Next, instances of the four epistemic practices explained above were identified. These were then compared and contrasted across the cases in order to identify relevant points of distinction between them. These were informed by the theoretical perspective, but reflective of the empirical details and distinctions particular to each partnership discerned inductively within this framework. These findings answer the first Research Question, and are presented below. The naming of each practice (in subheadings) captures features of these practices that connect to the wider epistemic practices approach while signalling empirically particular qualities.

The remaining steps focused on the second Research Question, first comparing the cases, now in terms of profession/client positioning and broader characteristic differences (presented in Table 2 in the Discussion section). Finally, the analysis stepped back from the detail of each case in order to pinpoint key epistemic aspects of professional-client partnership work (see Conclusions and Table 3). This further analytical distillation highlights epistemic features that are key aspects of the accomplishment of partnership, and lines along which the enactment of partnership varies in practice.

\section{Epistemic practices enacted by Catherine and Ariella}

The interaction between Catherine and Ariella took place in a day-stay facility (see Table 1). The mother sought professional help with getting her 16-month-old daughter Lila to sleep and to self-settle after waking during the night. Ariella was experiencing significant and sustained exhaustion, leaving her unable to consider returning to work. Hers was a 'blended' family, involving care for her 9-year-old step daughter. Ariella had history of depression following birth of her first son (now 20 years old), reported her ex-husband's violence towards her, and explained that her current husband was not particularly involved in care for Lila. Ariella had recently been prescribed medications to address a problem with her thyroid gland. Catherine's work with Ariella was regarded as successful: several weeks later, Ariella reported Lila's improved sleep behaviours and reduced maternal exhaustion, which contributed to her being able to find employment. 
Catherine needed to learn about Ariella's current situation and relevant aspects of her history $^{2}$. She began with a set of questions about the family (ages of children, prior relationships etc), then focused her information-gathering practices on the issue of sleep and settling. This positioned Ariella as knowledgeable about her own parenting practices, providing epistemic resources that informed Catherine's subsequent actions and suggestions.

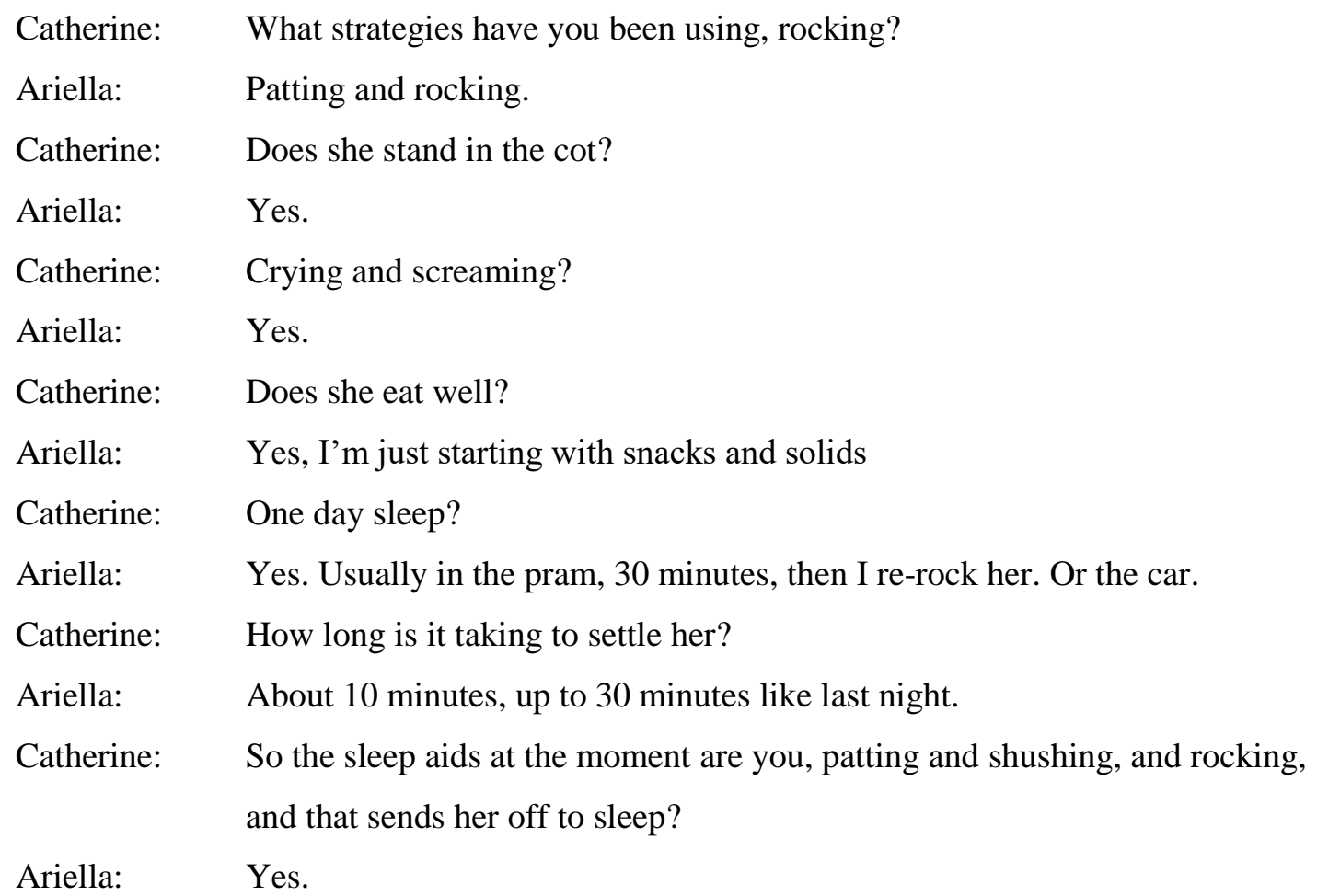

Catherine's questions solicited concrete descriptions of habits or patterns, creating an image of typical mother-child interactions around sleep and settling. Here the partnership unfolded in an asymmetrical to-and-fro between professional question, and client answer which informed further professional questions. Catherine led the discussion, and in this practice the mother's role was as knowledgeable responder offering relevant information. Given Ariella's anxiety and history of depression, knowledge of Ariella's feelings was recognised as an important epistemic resource. Catherine framed related questions as enabling identification of strategies that would be acceptable to Ariella: 'I need know to what effects it has on you so when we talk about strategies I'm aware, it's about what you are comfortable with too?'. From this point other epistemic resources could be connected, and a second epistemic practice of reasoning diagnostically could emerge. 
Knowledge of Ariella and her family was re-worked by creating an epistemic framing based on Catherine's generalised knowledge as a professional. Models and concepts from her child and family nursing field were mobilised to frame Ariella's struggle as a certain kind of problem to which a range of 'strategies' (interventions in the form of changes to sleep and settling processes) could be applied. Catherine's primary diagnosis was that the sleep and settling issues related to Lila's dependence on her mother's presence as a sleep aid; thus the interventions flowing from this involved the concept of 'independent sleep associations' (see Hopwood \& Clerke 2016). Catherine's reasoning reframed the problem as one of developing Ariella's capacity to help Lila construct independent sleep associations by consistently enacting new settling strategies.

However, such reasoning and the concepts involved could only make a difference if Ariella was enrolled into this way of thinking and her position within the problem as now epistemically framed - the mother as needing to meet demands of being consistent in new interactions with Lila. Accomplishing this relied on Catherine making ways of reasoning through professional concepts explicit:

Catherine: I'm thinking about independent sleep associations, meaning things that help her but which aren't us. During the learning process she will still depend on us for help, we will go in and come out as she's calming. Babies love predictability. It's important for her to see you come and go. She needs to get the idea that you won't be there all the time when she's sleeping.

Catherine returned to the practice of checking in on Ariella's feelings. Instead of referring to past instances, this was now framed to the prospect of future changes:

Catherine: If you're feeling less anxious now, with the thyroid diagnosis and meds [medications] working, do you feel up to trying?

Ariella: $\quad$ Yes, I couldn't before, but I'll give it a go now.

Catherine: She needs that practice. The more consistent you can be with the sleep and settling, the quicker the process will be [...] Once she gets practice, she can dissociate the patting and rocking to sleep, and she won't need it. 
Diagnostic reasoning, informed by epistemic resources including knowledge of the family and general principles, was made visible and used to enrol the mother into a commitment to trying something new. However, this knowledge was not yet actionable as the connection between the general and particular remained unspecified in many important respects. This was accomplished through the epistemic practice of recontextualising.

Recontextualising knowledge from general principles and patterns to specific interventions

The practice of recontextualising drew on professional knowledge as articulated by Catherine and represented materially in sheets relating to developmental milestones and children's sleep cycles, which buttressed Catherine's knowledge claims. In the excerpt below, Catherine explained how the suggested strategies were grounded in knowledge about sleep cycles. This produced an asymmetry between her and the parent in terms of epistemic authority, in which the expectation is that the mother becomes enrolled in a more professional way of knowing (see Discussion):

Catherine: Here's another sheet about sleep cycle, so you can share with your husband. Most of our sleep is deep sleep, but for babies most is light sleep and the cycle is shorter. That explains why she is rousing more easily. It's not her fault, she's not naughty, it's just her body. She'll still want some comfort to go back to sleep if she wakes, because she's likely coming out of and going back into light sleep.

In this way, Catherine linked generalised knowledge to this particular baby in terms of her reported sleep behaviours and the expected pace of change. Making knowledge actionable rested upon connecting general concepts of sleep cycles not just with Lila, but with her sleep state at specific moments. The latter required embodied testing, and Catherine returned to Ariella's own wellbeing and expectations of change, enriching the framing of the problem and embedding the mother's positioning in relation to it: 'Set the bar low and be surprised when it goes well. It's important with the strategies that they are doable for you'. 
Knowledge was also worked on by extracting general principles from a specific situation at hand. This established how professional knowledge and the overall epistemic framing was relevant to Lila and Ariella. One such situation occurred when the baby toddled out of the room:

Catherine: She'll come back to you, you're that secure base for her. She's exploring the world now, but coming back to you. Actually the same is important in settling. It's kind of like a separation for her. She needs to know you are around, but she can be quite confident on her own if she knows that secure base is available when she needs it, just like now - oh here she comes back! [...] Being predictable is important, so that going to the cot is not a shock for her.

The epistemic resources activated in this recontextualising work were drawn from Catherine's professional knowledge, frequently connecting with knowledge Ariella had provided about herself and her situation. This positioned Catherine as the main knowledgeable actor whose actions were informed by and sensitive to the mother's context, and the mother as a learner who gained access to new strategies of relating to her child by entering and sharing Catherine's epistemic framing.

\section{Testing knowledge claims and suggestions}

Recontextualised knowledge became actionable as it was applied and tested in embodied interactions between Ariella and Lila. Ariella was positioned as a key actor in this process, while Catherine offered suggestions and interpreted what unfolded between the mother and child. Proposed interventions were trialled to assess whether they worked as intended with Lila, and whether Ariella was capable of enacting the suggested settling strategies. To prepare for this, Catherine repeated the main principles they had arrived at so far, and turned to practical instructions, making knowledge actionable in provisional and prospective terms. This was informed by epistemic resources organised around an if/then procedural logic:

Catherine: Once you put her down, she's down. If she stands straight away, I'd leave. If you stay, that gives her a confused message. "Night-night, love you", then 
leave. Maybe go and get a glass of water, pop to the loo. Something short that brings you back. Expect her to cry. Try to add words to what's she's saying. "Mum come back!" Some cries are angry or confused. If you're changing something she will be a bit confused at first. Crying is her only way to communicate that. Try talking through the door. Shush, time for sleep. Start with low intervention and build to more. If you start with everything, you've nowhere to go.

Catherine secured Ariella's agreement to try something new, then led a process of connecting this particular moment with the general principles associated with sleep needs:

Catherine: You want to put her in the pram? I can help with that? Or do you want to practice here? How are you feeling?

Ariella: $\quad$ Yes let's try.

Catherine: It's a different environment. See how it goes. Let's think about her sleep needs again. Has she had enough to eat? Yes, she's had a sandwich and a good bottle. She's had a bit of time for the milk to settle. The pram is always there too. I can talk you through the cries.

Ariella then took Lila into a nursery, and went through her normal way of tucking the child in, talking gently and shushing. As predicted, Lila cried when Ariella left the room. Catherine's epistemic focus shifted to parallel occupations with making knowledge claims based on interpreting the child's behaviours, assessing Ariella's comfort in the process, and enrolling her into enacting the practices that her reasoning and recontextualising suggested were likely to be helpful. This involved providing Ariella with epistemic resources that helped her read the situation in a way other than 'I have to go in as soon as Lila cries and stay until she settles', including resources linked with empathy, and an if/then procedural logic that reflected the provisional nature of the suggestions:

Catherine: I suggest spending a short time in when you go back in, because staying might fuel her distress - she's expecting a cuddle but you're not giving one, so that can confuse and rev her up. (...) I hear a confused "where have you gone?" cry. [Listens] Ah that's anger - do you hear that "rrrr!"? If I was her I'd be thinking "Where am I?".

[...] 
Catherine: Now's not the time to go in... She's crying now, but not distressed. She's winding down a bit. When you go in, if she's standing then lie her down. She may go straight up again. That's okay, no fight. Respect her wish to stand.

\section{Epistemic practices enacted by Sophie and Masha}

The interaction between Sophie and Masha comes from a series of home visits that extended over many months (see Table 1). The service was offered to help with ongoing difficulties Masha had adjusting to parenting, including her high levels of anxiety and the risk of prolonged isolation given her fear of going out on foot. Morgan was 10 weeks old at the time the observation was conducted. This visit was typical of the way the partnership unfolded, switching focus and looping back to prior issues rapidly as Masha raised new issues and Sophie sought to address them. Morgan was Masha and her husband David's first-born. David was not present during the home visit, was generally described as supportive and actively engaging in caregiving, and had a current diagnosis of depression. After the visit, Sophie's work with Masha continued its complex set of trajectories in which some issues found resolution, others proved more belligerent, and new ones arose.

Collecting information and working on its status as an epistemic resource

Like Catherine, Sophie collected information from the parent, but she sought other kinds of information for other purposes, co-producing different epistemic resources in the process. Sophie's questions focused not just on what Masha knew, and her feelings, but how she knew it. This positioned Masha as a different kind of knower, and had implications for other epistemic features of their partnership.

If Masha reported a specific incident, Sophie probed Masha's feelings and responses. When Masha mentioned taking Morgan to hospital and the doctor saying he might have whooping cough, Sophie asked 'How did you and your husband react then?'. Masha's account of how difficult this was provided opportunities for Sophie to praise her for doing something so hard, emphasising how important it was that her husband had accompanied her. Descriptions of 
concrete events were thus transformed into epistemic resources that connected with the mother's anxiety and opened pathways pointing to what was working well for them as a family and what could help them in future. When Sophie asked again about Masha's feelings, she replied she would remain anxious until Morgan was one year old, because his immune system would be weak until then. Sophie replied:

Sophie: $\quad$ Yes, you're right there is a change around about one year. But I'm also hearing the confidence you had to deal with that scary situation, not just one doctor, but also to protect him when you were in the hospital.

Sophie legitimised Masha's claims to knowledge about immune systems, but challenged her framing as anxious, using the account of the hospital visit to highlight the mother's strengths ${ }^{3}$. Later, by asking 'What does he do to let you know he's excited?', Sophie elicited a detailed account of Morgan's behaviour that is then built on to allay Masha's concerns about his playfulness, and strengthen the mother's view of her parenting:

Masha: Oh he smiles, and laughs. When I'm holding him sometimes, we just look at each other for a moment and he smiles, or giggles. And we just sit and watch him on the mat he kicks his legs and smiles, and looks at us too. When I massage him, or just hold him, I watch him and he looks at me, he smiles a lot.

Sophie: $\quad$ Those little stops, when you gaze together and wonder, they are like food for his brain. He's got this big exciting world he's just getting to know, and you're helping him connect all the stars together.

\section{Reasoning diagnostically}

Diagnostic reasoning was enacted in a different way between Sophie and Masha compared to Catherine and Ariella, albeit still with asymmetrical roles. Sophie focused on activating the mother's reasoning, delving deeper and asking questions that addressed Masha's knowledge. This went beyond Masha as knowledgeable about her family, to her participation in the practice of reasoning:

Masha: $\quad$ Even when I'm breastfeeding him, he's looking at me. 
Sophie: What is in your mind at that time, when he's looking at you like that?

Masha: $\quad$ I don't know. Maybe he knows I'm someone.

Sophie: He knows you're the most important person.

Masha: $\quad H e$ does know me better than everyone else.

The emergence of Masha's insights depended on Sophie's questioning and the way she enriched the insight from a rather vague 'someone' to 'the most important person', which Masha then confirmed in her own terms. In another instance, Masha was worried about changes in Morgan's sleep patterns:

Masha: I just want to wait and see about this.

Sophie: $\quad$ That's a great idea, that looking, waiting, and wondering with him. Well done.

Masha: $\quad$ I can take him to the ED but there are so many sick people there.

Sophie: $\quad$ But you just described all these wonderful well things.

Masha: $\quad$ Yes and actually I didn't realise he played this morning too.

Sophie and Masha had to accept the impossibility of immediate solution or resolution. Sophie built on Masha's 'wait and see' as a helpful response to this, adding descriptions of Masha's actions that shifted the framing to parent-child interactions, not a passive state of helplessness. These connected with Masha's prior accounts of gazing and wondering (as illustrated above), enriching Masha's reasoning.

\section{Making the mother's knowledge actionable}

Sophie and Masha's partnership made the mother's knowledge actionable. Masha's actions became differently knowledgeable less through insertion of new professional knowledge, but more through changing the status of her own knowledge. When dealing with difficulty leaving the house, Masha's understanding of her own anxiety, knowledge of Morgan's increasing weight, and familiarity with her neighbourhood were activated as resources that helped to define a solution. This changed the epistemic framing from danger and anxiety to thinking about what would make going out possible, producing a commitment to action. It 
began when the idea of taking Morgan out in the pram came up and Masha queried if it was safe:

Sophie: What would make you feel safe, then, walking?

Masha: $\quad$ To the hospital is fine, because it is quiet, and I can use the baby carrier.

Sophie: $\quad$ Is he getting heavier in the carrier?

Masha: $\quad$ Yes.

Sophie: $\quad$ So maybe the pram could be something good for you. What it is that makes that difficult for you?

Masha: $\quad$ The intersections.

Sophie: What about the intersections worries you?

Masha: $\quad$ Maybe when cars turn it isn't safe, but there are no turns like that on the way to the hospital.

Sophie: $\quad$ So you might be able to do that today?

Masha: $\quad$ Yes. I could.

Often one epistemic practice was enabled and resourced by another. In the sequence below, making Masha's knowledge of the child's behaviours actionable relied on practices of reasoning:

Masha: $\quad$ Yesterday I tried, he was happy but then I put the cover over in the shopping centre and he was screaming.

Sophie: What is he telling you?

Masha: $\quad$ That he wants to look out.

Sophie: $\quad$ So could you leave the cover off?

Masha: $\quad$ Yes.

When working on Morgan's lack of sleep during the day, Sophie used Masha's knowledge of what happens at night as a resource. The idea of the pattern and its specific enactment came from Masha's description but Sophie made them actionable in relation to the daytime by changing the framing from a focus just on the child to one that linked the mother's actions with the child's experience:

Masha: He's okay at night.

Sophie: What do you do at night? 
Masha: $\quad$ Always the same just breastfeed and then to sleep.

Sophie: $\quad$ That's a routine for him, a pattern, but in the day you are changing each time. It seems he likes the routine of the night, so try giving him a pattern in the day too, that's nice and predictable for him... I'm hearing you've lost that pattern today. Trying lots of different things, maybe now he's older and so busy, that makes him excited, something different every time.

\section{Testing and contesting knowledge claims}

Masha made many knowledge claims. Often these were legitimised and reinforced by Sophie without any questioning of their status or unpacking. However, they were sometimes tested and contested. One way this was done was through practices of questioning and prompting the mother's reasoning:

\footnotetext{
Masha: $\quad$ For two weeks I had all the symptoms on PND [postnatal depression]. I will go to the GP on Sunday.

Sophie: What are those symptoms?

Masha: $\quad$ I Googled it. My mother-in-law told David I have PND because I'm too emotional and irrational so I Googled it.

Sophie: Which symptoms did it say that you think you have?

Masha: $\quad$ I'm oversensitive, and getting angry and anxiety they are all part of PND.

Sophie: $\quad$ Yes they are. What about reconnecting with the psychologist maybe?
}

Sophie treated Masha's self-diagnosis with cautious respect. She probed twice, asking for specific information which validated the knowledge claim. On this basis, a re-connection to the psychologist was offered, and taken up my Masha. Masha's knowledge claims were also tested and contested by relating them to the live, embodied realm that was also activated in Catherine and Ariella's work:

\footnotetext{
Masha: What's wrong with him? I just fed him.

Sophie: Maybe he's tired.

Masha: $\quad$ Okay I can try.

[Masha puts him in the cot; Morgan burbles and fidgets]

Masha: $\quad$ He's playing.
} 
Sophie: $\quad$ That's okay you can't make him sleep.

[Morgan starts to cry, Masha goes in, shushing and patting the mattress]

Sophie: $\quad$ You're just letting him know you're here.

Masha: But he's so wriggling, active.

Sophie: $\quad$ Can still be he's tired. I'd encourage the same pattern to the day again, and come in when he's grizzling a bit, before he gets to screaming.

[Morgan 'chats' to himself, burbling]

Masha: He's not tired.

Sophie: $\quad$ He is. He gets excited, he's on over time. That is him really tired... He does need some sleep in the day.

Masha: But that is impossible.

Sophie: $\quad$ You can give him the opportunity, without changing every time, give him a pattern.

Sophie contested a number of Masha's knowledge claims, showing that partnership can require professionals to adopt an opposing epistemic position. Over the sequence, Sophie became increasingly firm in her counter-claims, based on mounting evidence in the form of the child's behaviours. In the process Sophie reframed the problem from an 'impossible' one defined in terms of the child sleeping, to an achievable one defined in terms of the mother's role in helping the child calm down, relax and have the opportunity to sleep. Sophie (re)activated Masha's description of a more patterned daytime routine as an epistemic resource to buttress her counter-claims.

\section{Discussion}

Having documented the epistemic practices enacted when professionals work in partnership with clients, it remains to address the second research question: How do these practices position participants and generate distinct modes of partnership work? Each case could reasonably be deemed a partnership. Viewed in terms of frameworks such as the Family Partnership Model (Day et al. 2015) specify how partnership is accomplished, they followed a direction set by the parents' priorities, involved empathy and respect for parents' feelings and wishes, adapted to the specific situation of the family, and proceeded with the professional seeking rather than assuming the parent's agreement. 
Both cases responded to epistemic demands of participating in joint creation of actionable knowledge (Markauskaite \& Goodyear 2016), determining ways of working together (Guile 2014) and dealing with tensions relating to the use and status of professional expertise (Grundman 2017). Although there were asymmetries in both cases, understandings of the problem, diagnoses, and actionable responses to them all relied on both the professional and parent. Epistemic resources originated from professional principles and generalised knowledge, parents' experiences and insights, and from the unfolding partnership itself. Specialist knowledge and professional experience were crucial in both, as were the client's knowledge and experiences - Knorr Cetina's (2006) 'double weaving' between general knowledge and particular experiences was accomplished and activated through different practices, and with different effects, in each.

Nerland \& Jensen (2014) argued the need to differentiate between modes of epistemic engagement in professional practice, and an epistemic analysis reveals striking differences between the two cases. The epistemic practices positioned professionals and parents as different kinds of partners, associated with contrasting modes of partnership work. These distinctions are summarised in Table 2. Catherine and Ariella's partnership can be characterised in terms of strengthening the client from a professional epistemic perspective. An epistemic frame based on professional knowledge drew on information from the mother to inform diagnostic reasoning. Ariella's position shifted from knowledgeable about herself and her family, to being enrolled in a new framing, jointly testing it with her child, and committing to continuing with new epistemic practices of reasoning, recontextualising, interpreting and testing at home (not just following instructions).

Catherine and Ariella's partnership produced a more capable and confident mother in relation to the problem of sleeping. Ariella became able to approach this problem through a framing infused with Catherine's expertise and made actionable through epistemic resources largely drawn from Catherine's repertoire. The work of assessing, selecting, and recontextualising knowledge was mainly undertaken by Catherine, whose diagnoses and strategies were put to the test through checking with the mother and enrolling her into embodied interaction with the child. Catherine did not dictate the process as if the mother's knowledge and views counted for nothing, nor did she retreat from her own expertise: she thus managed the tension 
between bossy expert and getting stuck in the relationship in a distinctive way (Harris et al. 2014; Juhila et al. 2016; van Houte et al. 2015).

Sophie and Masha's partnership can be characterised as validating and augmenting the client's own epistemic contribution. Epistemic practices built the mother's status as a knower, making her knowledge actionable yet also subject to testing and confirmation. Throughout the shifting and recursive interactions, Sophie consistently disrupted Masha's own positioning as deficient and unknowledgeable.

In Sophie and Masha's partnership, demands relating to uncertainty were particularly intense. Fittingly, the approach was to construct a new epistemic basis from which the mother could act, relevant to the specific issues at hand, replete with generalisations across situations and potential as actionable in relation to other problems. This challenged the mother's sense of impossibility, and her doubts about her capacity to reason and act as a parent. Sophie navigated the tension between overbearing expert and failure to move beyond a supportive relationship in a very different way from Catherine. Her professional knowledge and experience informed each question, probe, empathic confirmation, suggestion and contestation - but were used to validate and render actionable client's contributions as a knower.

Practice and professional learning are entangled in both enactments of partnership. This includes learning about the client, although the client emerges differently depending on the approach. In the 'strengthening' mode, the client comes into view in terms of her knowledge of her past, her response to professional suggestions, and commitments to action. In the 'repositioning and validating' mode, the professional learns of the client in these ways but also as someone who works with and on knowledge. 


\begin{tabular}{|c|c|c|}
\hline & Catherine and Ariella & Sophie and Masha \\
\hline $\begin{array}{l}\text { Distinctive } \\
\text { characteristics of the } \\
\text { partnership work }\end{array}$ & $\begin{array}{l}\text {-Activating the client as } \\
\text { knowledgeable about the past to } \\
\text { inform professional knowledge } \\
\text { work } \\
\text {-Making professional diagnostic } \\
\text { reasoning explicit and available } \\
\text { for the client to use } \\
\text {-Recontextualising professional } \\
\text { knowledge to the client's situation } \\
\text {-Strengthening the client's } \\
\text { capacity to connect specific } \\
\text { instances to general principles } \\
\text {-Testing professional knowledge } \\
\text { claims and suggestions } \\
\text {-Enrolling the mother into newly } \\
\text { knowledgeable actions }\end{array}$ & $\begin{array}{l}\text {-Soliciting the client's } \\
\text { knowledge and building its status } \\
\text { as a legitimate and actionable } \\
\text { epistemic resource } \\
\text {-Activating and strengthening the } \\
\text { client's capacity to reason } \\
\text { diagnostically } \\
\text {-Strengthening the client's } \\
\text { capacity to generalise from } \\
\text { particular instances to other } \\
\text { instances and general principles } \\
\text {-Testing and contesting the } \\
\text { client's knowledge claims } \\
\text {-Building a new epistemic frame } \\
\text { through which the client } \\
\text { encounters, interprets, and acts in } \\
\text { response to problems }\end{array}$ \\
\hline $\begin{array}{l}\text { Epistemically } \\
\text { distinct mode of } \\
\text { partnership }\end{array}$ & $\begin{array}{l}\text { Strengthening the client from a } \\
\text { professional epistemic perspective }\end{array}$ & $\begin{array}{l}\text { Validating and augmenting the } \\
\text { client's own epistemic } \\
\text { contribution }\end{array}$ \\
\hline
\end{tabular}

\section{Conclusion}

Having address the two research questions, we now return to the broader gap in knowledge, highlighting what the analysis offers as an epistemic account of relational professional practices. This requires us to step back from each case in order to identify features of how partnership is accomplished epistemically, and lines along which this accomplishment can 
vary in practice. These further analytical distillations are presented in Table 3. Table 3 shows partnership unfolds through creation of epistemic frames, making knowledge actionable by moving between forms of knowledge, and allocating epistemic responsibilities. These lay out dimensions upon which enactments of partnership may be distinguished from each other. Such distinctions have implications for the kinds of knowledge generated through partnership, in other words, for learning. Table 3 may inform future analyses of relational work. It does not prescribe particular epistemic practices or positions in a normative way, but opens up what was previously a 'hazy' (Markauskite \& Goodyear 2014) aspect of professional practice.

Table $3 \quad$ Key epistemic aspects of professional-client partnership work

\begin{tabular}{ll}
\hline Aspect & Explanation \\
\hline Ways of creating an epistemic & $\begin{array}{l}\text { Specific situations or generalised knowledge can be taken } \\
\text { as the point of departure }\end{array}$ \\
\hline Means for making knowledge & $\begin{array}{l}\text { Movement between forms of knowledge is needed: from } \\
\text { actionable together }\end{array}$ \\
$\begin{array}{l}\text { specific and concrete to general and abstract and vice } \\
\text { versa }\end{array}$ \\
\hline How epistemic responsibilities & $\begin{array}{l}\text { Positioning of actors as knowers and knowledgeable; in } \\
\text { what ways each partner contributes to epistemic practices }\end{array}$ \\
\hline How learning is entangled with & Different enactments require and give rise to different \\
enactments of partnership & opportunities to learn (about the client, the problem, the \\
& practices required to work in partnership) \\
\hline
\end{tabular}

The value of this analysis can be illustrated in relation to widely documented tensions experienced by professionals torn between bossy expert or retreat from expertise (Juhila et al. 2016; van Houte et al. 2015). Traditionally this has been framed as a problem of who has epistemic authority and how that is dispensed with. The approach summarised in Table 3 frames this dilemma differently, pointing to variations in how epistemic aspects of partnership are enacted. It shifts the question from who knows what to what it becomes possible to know, what knowledge makes possible, what epistemic resources are activated and how they are related to one another. The enactment of collaborative work will always 
reflect contingencies of the problem at hand and context in which it is addressed (Guile 2014). Such variations in enactment can be understood in terms of the epistemic aspects shown in Table 3.

Changes in the relational nature of work create a need to look afresh in order to better understand how this work is done (Evetts 2014). In this paper we have taken an epistemic practices perspective into new terrain, focusing on professional-client partnership to reveal distinctions that cast important new light on this poorly understood feature of contemporary professional work. Partnership raises significant epistemified demands. Our analysis connects these broader issues with concrete interactions, through a focus on the knowledge at stake, how it is made to matter, and how it becomes a basis for action.

\section{Endnotes}

${ }^{1}$ Partnership can also be used to refer to relationships at a broader level, as in Billett et al.'s (2007) study of social partnerships. Our focus is on partnership as an interpersonal rather than inter-sectoral or inter-organisational accomplishment.

${ }^{2}$ Readers familiar with analyses of therapeutic discourses (eg. in psychotherapy) may note a resemblance with a sequence of documenting, defining and reframing a problem (see Avdi \& Georgaca 2007; Mattila 2001).

${ }^{3}$ Sophie's practices had features that some may note resonate with aspects of Solution Focused Brief Therapy, Systemic Therapy, or other approaches.

\section{References}

Aarsand, L. (2014). The knowledgeable parenting style: stance takings and subject positions in media encounters. International Journal of Lifelong Education, 33(5), 625-640, doi: $10.1080 / 02601370.2014 .909895$

Avdi, E. \& Georgaca, E. (2007). Discourse analysis and psychotherapy: A critical review. European Journal of Psychotherapy \& Counselling, 9(2), 157-176, doi: 10.1080/13642530701363445

Billett, S., Ovens, C., Clemans, A. \& Seddon, T. (2007). Collaborative working and contested practices: forming, developing and sustaining social partnerships in education. Journal of Education Policy, 22(6), 637-656, doi: 10.1080/02680930701625288

Cunningham, C. M. \& Kelly, G. J. (2017). Epistemic practices of engineering for education. Science Education, 101(3), 486-505, doi: 10.1002/sce.21271 
Damşa, C. \& Nerland, M. (2016). Student learning through participation in inquiry activities: two case studies in teacher and computer engineering education. Vocations and Learning, 9(3), 275-294, doi: 10.1007/s12186-016-9152-9

Day, C., Ellis, M. \& Harris, L. (2015). Family Partnership Model reflective practice handbook. London: Centre for Parent and Child Support for South London and Maudsley NHS Foundation Trust and King's College London.

Edwards, A. (2010). Being an expert practitioner: the relational turn in expertise. Dordrecht: Springer.

Edwards, A., Daniels, H., Gallagher, T., Leadbetter, J. \& Warmington, P. (2009). Improving interprofessional collaborations: multi-agency working for children's wellbeing. London: Routledge.

Eriksson, I. \& Lindberg, V. (2016). Enriching 'learning activity' with 'epistemic practices': enhancing students' epistemic agency and authority. Nordic Journal of Studies in Educational Policy, 2, doi: 10.3402/nstep.v2.32432

Eronen, R., Pincombe, J. \& Calabretto, H. (2010). The role of child health nurses in supporting parents of young infants. Collegian, 17, 131-141, doi: 10.1016/j.colegn.2010.04.001

Evetts, J. (2014). The concept of professionalism: professional work, professional practice and learning. In S. Billett, C. Harteis \& H. Gruber (Eds.), International handbook of researching professional and practice-based learning (pp. 29-56). Dordrecht: Springer.

Fenwick, T. (2012a). Coproduction in practice: a sociomaterial analysis. Professions \& Professionalism, 2(2), doi: $10.7577 / \mathrm{pp} / \mathrm{v} 2 \mathrm{i} 1.323$

Fenwick, T. (2012b). Learning among older professional workers: knowledge strategies and knowledge orientations. Vocations and Learning, 5(3), 203-223, doi: 10.1007/s12186-012-9074-0

Fowler, C., Rossiter, C., Bigsby, M., Hopwood, N., Lee, A. \& Dunston, R. (2012). Working in partnership with parents: the experience and challenge of practice innovation in child and family health nursing. Journal of Clinical Nursing, 21(21-22), 3306-3314, doi: 10.1111/j.1365-2702.2012.04270.x

Gartmeier, M., Bauer, J., Gruber, H. \& Heid, H. (2008). Negative knowledge: understanding professional learning and expertise. Vocations and Learning, 1(2), 87-103, doi: 10.1007/s12186-008-9006-1

Gherardi, S. (2006). Organizational knowledge: the texture of workplace learning. Oxford: Blackwell.

Grundmann, R. (2017). The problem of expertise in knowledge societies. Minerva, 55(1), 25, doi:

Guile, D. (2010). The learning challenge of the knowledge economy. Rotterdam: Sense Publishers.

Guile, D. (2011). Interprofessional Activity in the 'Space of Reasons': Thinking, Communicating and Acting. Vocations and Learning, 4(2), 93-111, doi: 10.1007/s12186-011-9052-y

Guile, D. (2014). Professional knowledge and professional practice as continuous recontextualisation. In M. Young \& J. Muller (Eds.), Knowledge, expertise and the professions (pp. 78-92). Abingdon: Routledge.

Harris, L., Wood, L. \& Day, C. (2014). An ethnographic study into the Family Partnership Model: implementation and sustainability. London: Centre for Parent and Child Support / South London and Maudsley NHS Foundation Trust. 
Hopwood, N. (2016). Professional practice and learning: times, spaces, bodies, things. Dordrecht: Springer.

Hopwood, N. (2017a). Agency, learning and knowledge work: epistemic dilemmas in professional practices. In M. Goller \& S. Paloniemi (Eds.), Agency at work: an agentic perspective on professional learning and development (pp. 121-140). Dordrecht: Springer.

Hopwood, N. (2017b). Expertise, learning, and agency in partnership practices in services for families with young children. In A. Edwards (Ed.) Working relationally in and across practices: cultural-historical approaches to collaboration (pp. 25-42). Cambridge: Cambridge University Press.

Hopwood, N. \& Clerke, T. (2016). Professional pedagogies of parenting that build resilience through partnership with families at risk: a cultural-historical approach. Pedagogy, Culture \& Society, 24(4), 599-615, doi: 10.1080/14681366.2016.1197299

Hopwood, N. \& Edwards, A. (2017). How common knowledge is constructed and why it matters in collaboration between professionals and clients. International Journal of Educational Research, 83, 107-119, doi: 10.1016/j.ijer.2017.02.007

Jensen, K., Lahn, L. C. \& Nerland, M. (2012). Professional learning in the knowledge society. Springer Science \& Business Media.

Jensen, K., Lahn, L. C. \& Nerland, M. (2012). Introduction - professional learning in new knowledge landscapes: a cultural perspective. In K. Jensen, L. C. Lahn \& M. Nerland (Eds.), Professional learning in the knowledge society (pp. 1-24). Rotterdam: Sense Publishers.

Juhila, K., Hall, C. \& Raitakari, S. (2016). Interaction during mental health floating support home visiting: managing host-guest and professional-client identities in home-spaces. Social \& Cultural Geography, 17(1), 101-119, doi: 10.1080/14649365.2015.1042401

Knorr Cetina, K. (2001). Objectual practice. In T. R. Schatzki, K. Knorr Cetina \& E. von Savigny (Eds.), The practice turn in contemporary theory (pp. 175-188). London: Routledge.

Knorr Cetina, K. (2006). Knowledge in a knowledge society: five transitions. Knowledge, Work and Society, 4(3), 23-41.

Knorr Cetina, K. \& Reichmann, W. (2015). Professional epistemic cultures. In I. Langemeyer, M. Fischer $\&$ M. Pfadenhauer (Eds.), Epistemic and learning cultures at the university of the 21st century (pp. 18-33). Weinheim: Beltz Juventa.

Mattila, A. (2001). Seeing things in a new light: reframing in therapeutic conversation (Rehabilitation Foundation Research Report 67). Helsinki: Rehabilitation Foundation.

Markauskaite, L. \& Goodyear, P. (2014). Professional work and knowledge. In S. Billett, C. Harteis \& H. Gruber (Eds.), International handbook of researching professional and practice-based learning (pp. 79-106). Dordrecht: Springer.

Markauskaite, L. \& Goodyear, P. (2016). Epistemic fluency and professional education: innovation, knowledgeable action and working knowledge. Dordrecht: Springer.

Nerland, M. (2008). Knowledge cultures and the shaping of work-based learning: the case of computer engineering. Vocations and Learning, 1(1), 49-69, doi: 10.1007/s12186-007-9002-x 
Nerland, M. \& Jensen, K. (2014). Changing cultures of knowledge and professional learning. In S. Billett, C. Harteis \& H. Gruber (Eds.), International handbook of researching professional and practicebased learning (pp. 611-640). Dordrecht: Springer.

Prior, L. (2003). Belief, knowledge and expertise: the emergence of the lay expert in medical sociology. Sociology of health \& illness, 25(3), 41-57.

Säljö, R. (2009). Learning, theories of learning, and units of analysis in research. Educational Psychologist, 44(3), 202-208, doi: 10.1080/00461520903029030

Schön, D. (1987). Educating the reflective practitioner: Toward a new design for teaching and learning in the professions. San Francisco: Jossey-Bass.

Shaffer, D. W. (2006). Epistemic frames for epistemic games. Computers \& Education, 46(3), 223-234, doi: 10.1016/j.compedu.2005.11.003

Smith, J., Swallow, V. \& Coyne, I. (2015). Involving parents in managing their child's long-term condition - a concept synthesis of family-centered care and partnership-in-care. Journal of Pediatric Nursing, 30(1), 143-159, doi: 10.1016/j.pedn.2014.10.014

van Houte, S., Bradt, L., Vandenbroeck, M. \& Bouverne-De Bie, M. (2015). Professionals' understanding of partnership with parents in the context of family support programmes. Child \& Family Social Work, 20(1), 116-124, doi: 10.1111/cfs.12067 